\title{
THEODOR HERZL, FUNDADOR DEL SIONISMO POLÍTICO*
}

\author{
Pedro Cobo**
}

\section{Enjulio del año pasado se cumplie-}

ron cien años del fallecimiento de Theodor Herzl, el padre del sionismo político. El 14 de mayo de 1948 -cuarenta y cuatro años después de su muerte- su sueño se cumplía en el momento en el que Ben Gurión proclamaba solemnemente el nacimiento del estado de Israel: después de dos mil años, los judíos podían volver a la tierra de sus ancestros. Si Herzl pudiera salir de su tumba podría ver gran parte de sus sueños realizados: un Estado judío en Palestina; grandes edificios modernos; no sólo una, sino muchas universidades con prestigio mundial; afamadas orquestas; una sociedad plural, cosmopolita y de marcado acento occidental... Sin embargo, me temo que se sentiría profundamente decepcionado al comprobar cómo dos de las grandes metas que perseguía con su Estado judio o su Estado de los judios ${ }^{1}$ están lejos de

* Este trabajo es resultado de una reciente investigación en la Universidad Hebrea de Jerusalén.

** Departamento Académico de Estudios Generales y Estudios Internacionales, ITAM.

${ }^{1}$ Generalmente se ha traducido su obra más famosa, Der Judenstaat, como el Estado judío, sin embargo hay quienes piensan que es una traducción errónea y prefieren la de $E l$ Estado de los judios. Cfr. Muhammad Ali Khalidi, "Utopian Zionism or Zionism Proselytims? A Reading of Herzl's Altneuland", Journal of Palestine Studies, 30, 4, verano 2001, p. 55. Gideon Shimoni afirma categóricamente, al analizar otra de las obras de Herzl, Altneuland, que el estado descrito por Herzl en esa obra era "definitivamente un Estado para los judios más que un Estado judio". Cfr. The Zionist Ideology, 1995, Hannover, Brandeis University Press, p. 94-5. 
alcanzarse: el encontrar un lugar en donde los judíos pudiesen vivir en paz y acabar con el antisemitismo. Difícilmente se podría decir que el Estado de Israel vive en paz y, en cuanto al antisemitismo, es evidente que ha aumentado tras los acontecimientos de los últimos tres años en Israel y Palestina.

El sueño de Herzl está todavía a medio camino y el final del túnel está lejano. Pero en este escrito no pretendo comparar la visión política de Herzl con la realidad política del actual Estado de Israel. Mi propósito en este centenario es más sencillo: explicar en primer lugar cuál fue el proceso por el cual Herzl pasó de ser un judío asimilacionista típico -había que desaparecer entre los gentiles- a ser el padre del movimiento político que llevaría a la existencia del único estado del mundo que se autodenomina con el apelativo de judío; en segundo lugar pretendo hacer un recorrido por su vida diplomática y política. Finalmente se terminará con una reflexión acerca de lo que considero sus mayores aciertos y fracasos.

\section{Herzl, prototipo de judío asimilacionista}

Herzl nació en 1860 en el seno de una acaudalada familia judía en Budapest. Educado en magiar y alemán eligió la segunda como un medio de integrarse en la cultura germánica. ${ }^{2}$ Trasladado a Viena en 1878 , donde estudió Leyes, pronto se dedicó al periodismo y a la creación literaria. Aunque muchos de sus amigos eran judíos, lo mismo que su mujer, y trabajó en el famoso periódico Neue Freie Press, dirigido por judíos, su contacto con el judaísmo cultural y religioso fue mínimo: no asistía a la sinagoga, desconocía el hebreo y hasta muy tarde nunca tuvo especial interés en temas relacionados con el mundo judío; incluso cuando escribió su obra más famosa, El Estado judio, desconocía las propuestas de otros judíos para solucionar el llamado 'problema judío'. Por el contrario se puede decir que hizo todos los esfuerzos posibles por asimilarse dentro de la cultura progermánica característica de muchas

${ }^{2}$ Ibid., p. 89. 
de las asociaciones universitarias de su época. Herzl sería así un ejemplo claro del judío austríaco descrito por Zweig en su extraordinaria obra El mundo de ayer: ${ }^{3}$

...la adaptación al medio del pueblo o del país en cuyo seno viven, no es para los judíos una medida de protección externa, sino también una profunda necesidad interior. Su anhelo de patria, de tranquilidad, de reposo y seguridad, sus ansias de no sentirse extraños, les empujan a adherirse con pasión a la cultura de su entorno. Y seguramente en ninguna otra parte (salvo en la España del siglo XV) esta unión se realizó tan fructífera y felizmente como en Austria. Establecidos en la ciudad imperial durante más de dos siglos, los judíos encontraron en ella a un pueblo despreocupado, dado a la conciliación.

Estando en la Universidad de Viena se hizo miembro de la Akademische Lesehalle (club de lectura) y de la fraternidad Albia, organizaciones nacionalistas alemanas que, implícitamente, esperaban de sus miembros judíos el olvido de cualquier característica cultural propia con el fin de que adoptaran las alemanas. ${ }^{4}$ Herzl aceptó las condiciones: se convertiría en un progermánico ${ }^{5} \mathrm{y}$, por lo tanto, en opositor de la multietnicidad del Imperio de los Habsburgo. Su asimilacionismo llegó tan lejos que incluso pensó en su propio bautismo, como escribió en sus diarios, aunque reconociera que sólo habían sido "vagos deseos nacidos de la debilidad de la juventud". 6 También pensó en el bautismo de su hijo, aunque no lo hiciera ni tampoco lo circuncidara: ${ }^{7}$

Yo jamás me convertiría pero apoyo la conversión. En mi caso el asunto está resuelto, pero me molesta mucho cuando pienso en mi hijo Hans.

${ }^{3}$ Stefan Zweig, El mundo de ayer: memorias de un europeo, 2001, Barcelona, El Acantilado, p. 40, trad. J. Fontcuberta y A. Orzeszek.

${ }^{4}$ Jacques Konberg, Theodor Herzl: from Assimilation to Zionism, 1993, Bloomington and Indianapolis, Indiana University Press, p. 35.

${ }^{5}$ Ibid., p. 48.

${ }^{6}$ Ibid., p. 81.

${ }^{7}$ Amos Elon, Herzl, 1975, New York, Holt, Rinehart \& Winston. Citado en Paul Johnson, La historia de los judios, 1991, Buenos Aires, Javier Vergara, p. 397-8. 
Me pregunto si tengo derecho de agriar y ensombrecer su vida como se ha visto agriada la mía. Por lo tanto, es necesario bautizar a los niños judíos antes de que puedan oponerse y antes de que la conversión sea interpretada como una debilidad de su parte. Deben desaparecer en la multitud.

Además de su asimilacionismo, la visión de su propio pueblo tampoco era la más adecuada para convertirse posteriormente en el líder del sionismo: lo consideraba un 'pueblo retrógrado y afeminado ${ }^{8}$ y gustaba de hacer bromas antisemitas, ${ }^{9}$ de lo que dejó muchas muestras en sus cartas, diarios y novelas. Así, en 1885 escribió en una carta, tras una cena en una casa burguesa judía: "Ayer una gran soirée en la casa de Treitel. Alrededor de treinta o cuarenta pequeños y feos judíos. Ninguna vista consoladora."10 Y durante unas vacaciones en Ostende en carta a sus padres: "Muchos judíos vieneses y de Budapest en la playa. El resto de los veraneantes muy agradables." 11 Su fenotipo tampoco le agradaba especialmente: "tienen un cuerpo y fisonomía distinta, una extraña, e incluso, ay, una despreciable fisonomía". ${ }^{12}$ Eso era debido, según él, a la endogamia. Consideraba que sus correligionarios habían sido las sanguijuelas "de la Edad Media y, también hay que reconocerlo, de los tiempos modernos". ${ }^{13}$ Entendía que su propio pueblo tenía un carácter 'avaricioso y deseoso de botín'. ${ }^{4}$

En general, su visión acerca del pueblo judío procedía del antisemitismo de los gentiles. Esa percepción persistió incluso después de su conversión al sionismo. En sus memorias, iniciadas tras abrazar la fe sionista, son frecuentes críticas al carácter judío. Ante las acusaciones que se le hicieron acerca de su supuesto interés económicos en la emigra-

${ }^{8}$ Michel Warschawski, Israel-Palestina: La convivencia binacional, 2002, Madrid, Catarata, p.41.

${ }^{9}$ Johnson, op. cit., p. 397-8.

${ }^{10}$ Konberg, op. cit., p. 72.

11 Johnson, p. 397.

12 Ibid., p. 24.

${ }^{13}$ Ibid., p. 21.

${ }^{14}$ Ibid., p. 21. 
ción a Palestina escribiría: "Nuestros judíos simplemente no pueden creer que nadie actúe por un acto de convicción moral"; 15 en mayo de 1900, cansado de los enormes problemas con los que se estaba enfrentando escribió en sus memorias: "Pensé en un epitafio apropiado para mí: Tenía una opinión demasiado buena acerca de los judíos."16 $\mathrm{O}$ en su novela Altneuland -escrita en 1902 dos años antes de su muerteun judío afirma: "Nos preocupamos por convicciones? Yo sólo conozco dos: negocios y placer". 17 Sus ataques más duros iban en contra de los judíos ricos; y así escribiría en enero de 1897: "Los judíos acaudalados, es cierto, continúan comportándose miserablemente como en el pasado."18 Su visión del judaísmo era conocida y así uno de sus amigos, Schnitzler, también judío, - quien le ayudó a la publicación de su primera novela acerca del judaísmo El nuevo gueto- escribiría en una de sus obras: "Sólo he llegado a conocer bien a un antisemita y me temo que estoy obligado a admitir ....que fue un bien conocido líder sionista."19

Como queda dicho, Herzl tomó de escritores antisemitas su visión del judaísmo pero, a diferencia de la literatura antisemita, él consideraba que ese carácter había sido provocado por la humillación infligida durante siglos por parte de los gentiles: ${ }^{20}$ los judíos habían sido víctimas no agentes de ese carácter, según Herzl, poco noble.

Sin embargo, y unida a su anterior visión acerca de los judíos -ampliamente demostrada a través de sus múltiples escritos- conservaba cierto sentido de fidelidad a su pueblo y el orgullo de sentirse judío. Así, su sentido filial le impidió tanto bautizarse como bautizar a su hijo $\mathrm{o}^{21} \mathrm{o}$, cuando para publicar un artículo se le sugirió tomar un seudónimo para ocultar su origen judío, se enfureció. ${ }^{22}$ Se puede decir que Herzl

${ }^{15}$ Marvin Lowenthal, ed., The Diaries of Theodor Herzl, 1956, New York, The Dial Press, p. 199.

${ }^{16}$ Ibid., p. 325.

${ }^{17}$ Konberg, op. cit., p. 72.

${ }^{18}$ Lowenthal, op. cit., p. 201.

${ }^{19}$ Konberg, op. cit., p. 154.

${ }^{20}$ Ibid., p. 35. Shimoni, op. cit., p. 91.

${ }^{21}$ Konberg, op. cit., p. 84.

${ }^{22}$ Ibid., p. 81. 
vivió en una tormentosa ambigüedad en la que coexistían el deseo asimilacionista con sentimientos de superioridad a causa de la misma razón. ${ }^{23}$ Como diría Avineri, la vida de Herzl fue una 'atormentada odisea intelectual'. ${ }^{24}$

\section{El antisemitismo: el detonador del cambio}

Tradicionalmente se ha explicado el paso al sionismo -desde un posición de alejamiento al judaísmo-al caso Dreyfus, que saltó a la opinión pública en 1894. Como es conocido, el capitán del ejército francés Dreyfus fue acusado de haber vendido información confidencial a Alemania. Juzgado y condenado, Dreyfus fue enviado a la Isla del Diablo. Posteriormente se demostró que Dreyfus era inocente. Entre muchos intelectuales pronto se empezó a pensar que la acusación era falsa y que había sido condenado por el único hecho de ser judío. Lo cierto es que el caso Dreyfus más que un juicio a una persona fue a toda la comunidad judía; lo que se planteaba no fue si el capitán era culpable o no sino si un judío podía ser verdaderamente francés y por tanto leal a su patria. Zola expondría con su elegante pluma la acusación que hacían los antisemitas al pueblo judío: ${ }^{25}$

Se les ha pretendido aplastar [a los judíos] junto con el capitán Dreyfus, se ha intentado convertir el crimen de uno de ellos en el crimen de la raza entera. Todos son traidores, todos vendidos, todos condenados. ¡Cómo no va a protestar con furia esa gente, cómo no van a tratar de rebelarse, de devolver golpe por golpe en esta guerra de exterminio de que son víctima! Es comprensible que anhelen apasionadamente ver cómo resplandece la inocencia de su correligionario; y si creen que pueden lograr la rehabilitación de Dreyfus, ¡ah!, con qué ánimo deben perseguirla!

${ }^{23}$ Shimoni, op. cit., p. 89; Konberg, op. cit., p. 81.

24 Shlomo Avineri, "Theodor Herzl's Diaries as a Bildungsroman," Jewish Social Studies, 5, 3, primavera/verano, 1999, p. 1.

${ }^{25}$ Emile Zola, Yo acuso: la verdad en marcha, 1998, Barcelona, Tusquets, p. 28, trad. José Elías. 
El mismo Herzl en 1899 reconocería que ese caso flagrante de antisemitismo había sido el causante de su conversión al sionismo. ${ }^{26}$ Incluso algunos de sus amigos, como es el caso de Stefan Zweig -a quien Herzl invitó a unirse al movimiento sionista como codirector- ${ }^{27}$ lo creían así ${ }^{28}$ también el libro acerca del sionismo más citado -y uno de los más serios- el de Hertzberg publicado en 1997, así lo recoge. ${ }^{29}$ Sin embargo desde hace tiempo las afirmaciones de Herzl se han puesto en duda ${ }^{30}$ ya que su novela El nuevo gueto-donde se percibe claramente una posición alejada de su anterior postura asimilacionista y aboga por la diferencia judía- es anterior al caso Dreyfus; aunque el mismo Herzl llegó a afirmar que el origen de esa novela fue debida al famoso afaire. ${ }^{31} \mathrm{El}$ análisis minucioso de su correspondencia y de sus diarios revelan que las observaciones de Herzl hacía el caso Dreyfus fueron tangenciales ${ }^{32}$ e incluso que en un inicio -al igual que la mayoría de los intelectuales, incluidos los judíos-no pensaba que fuera inocente, aunque tampoco aceptó sin reservas su culpabilidad. ${ }^{33}$ Lowenthal interpreta esa falta de exactitud "en el mejor de los casos como un mito apropiado, un dramático escorzo de los hechos"34 y Konberg la explica por la necesidad en 1899-año en el que escribió que el caso Dreyfus le había llevado al sionismo-de mantener el encanto de su carisma en el momento que ya era conocido internacionalmente como líder del sionismo ${ }^{35}$ y quizá debido a que él fue uno de los primeros que empezó a creer en su inocencia (en 1896 escribió a un amigo diciéndole que pensaba que

${ }^{26}$ Lowenthal, op. cit., p. xix.

${ }^{27}$ Zweig, op. cit., p. 145.

28 Ibid., p. 139-141.

${ }^{29}$ Arthur Hertzberg, The Zionist Idea: A Historical Analysis and Reader, 1997, Philadelphia, The Jewish Publication Society, p. 202.

${ }^{30}$ Lowenthal, op. cit., p. xix.

${ }^{31}$ Konberg, p. 190.

${ }^{32}$ Avineri, p. 7.

${ }^{33}$ Konberg, p. 196.

${ }^{34}$ Lowenthal, p. xix.

${ }^{35}$ Konberg, p. 200. 
quizá Dreyfus fuera inocente); ${ }^{36}$ es decir, Konberg sugiere que pudiera ser una alteración de la realidad basándose en algunos hechos reales.

Sea como fuere, lo cierto es que el paso de asimilacionista a sionista no fue debido al caso Dreyfus. Más bien se debió al antisemitismo creciente en su Austria natal y en las zonas germánicas en general. ${ }^{37}$ Dentro de Albia, la asociación universitaria a la que pertenecía Herzl, había división en torno a la admisión o no de judíos; a partir de 1880-1 se prohibió la entrada a más judíos. Ese mismo año Herzl se convirtió en miembro pasivo, pero en 1883 tras un homenaje a Wagner organizado por Albia se lanzaron gritos antisemitas y Herzl dimitió. Herzl no estuvo nunca en contra de que Albia rechazara el 'espíritu judío' -con lo que estaba de acuerdo- sino contra el antisemitismo racial que pretendía devolver a los judíos al gueto. ${ }^{38}$

Entre finales de los ochenta y principios de los noventa Herzl siguió siendo un judío ambivalente: ${ }^{39}$ habiendo hecho todos los esfuerzos por asimilarse se encontraba frente a un antisemitismo de nuevo cuño que se extendía por toda Alemania ${ }^{40}$ y Austria, el cual no sólo rechazaba al judío ortodoxo, aislado del mundo de los gentiles, sino también a los más asimilados, por el simple hecho de ser judíos.

Desde 1891 Herzl se convirtió en el corresponsal del Neue Freie en París y desde allí percibía alarmado - a través de sus periódicas visitas a Austria-el aumento del antisemitismo austríaco concretado en el ascenso de la Unión cristiana, que atacaba a los judíos por promotores del capitalismo; tampoco faltaron las viejas calumnias de sacrificios de niños. ${ }^{41}$ En ese año Herzl dio, por primera vez, muestras de preocuparse del antisemitismo. Escribió un esbozo de novela en donde criticaba a los judíos ricos como causantes del antisemitismo, mientras que los judíos

${ }^{36}$ Ibid., p. 198-9.

${ }^{37}$ Avineri, op. cit., p. 7-13.

${ }^{38}$ Konberg, p. 50.

${ }^{39}$ Ibid., p. 89.

${ }^{40}$ Alemania fue uno de los países en donde los judíos experimentaron un sentimiento de aceptación más profundo. Cfr. Gerald Messadié, Historia del Antisemitismo, 2001, Argentina, Javier Vergara, p. 280.

${ }^{41}$ Konberg, p. 96-7. 
pobres eran los que lo sufrían. ${ }^{42}$ Así seguía pensándolo años después, como lo dejaría reflejado en el capítulo dedicado al antisemitismo de su Estado judío, publicado en 1897. En él consideraba que el antisemitismo era producto de la envidia pero también entendía que era una 'supuesta autodefensa' ${ }^{43}$ de los gentiles, ya que una vez que los judíos salieron del gueto se sintieron obligados a "hacer una terrible competencia a la clase media [gentil]", 44 que provocaba que el antisemitismo aumentase "de día en día, de hora en hora, y tiene que seguir aumentando porque las causas siguen existiendo y no pueden ser eliminadas". 45

Para Herzl el odio al pueblo judío crecía en donde aumentaba el número de judíos ricos y pobres: los primeros generaban odio por razones obvias y los segundos, al caer bajo los partidos proletarios, eran despreciados por la capa media de los burgueses. ${ }^{46}$ Y además ese problema no tenía solución, ya que los gentiles al no aceptarlos ayudaban a ratificar a los judíos como un pueblo, lo que los segregaba y a su vez provocaba que aumentase el antisemitismo:

Somos un pueblo: los enemigos hacen que lo seamos, aun contra nuestra voluntad, como ha sucedido siempre en la historia. Acosados, nos erguimos juntos, y de pronto descubrimos nuestra fuerza. ${ }^{47}$

En 1892 escribió otros dos artículos acerca del antisemitismo en el Neue Freie Press. Entre 1892 y 1893 Herzl se iba alarmando cada vez más. Reconoció que la asimilación había sido un fracaso; ${ }^{48} \sin$ embargo no sabía hacia dónde ir, ya que la vuelta al judaísmo de sus antepasados no era una solución para él. ${ }^{49}$ Entendiendo que la causa

${ }^{42}$ Ibid., p. 99.

${ }^{43}$ Theodor Herzl, El Estado judio, 1946, Washington, Departamento Latino Americano de la Agencia Judía, p. 19, trad. Sigfredo Krebs.

${ }^{44}$ Ibid., p. 34.

${ }^{45}$ Ibid., p. 34-5.

${ }^{46}$ Ibid., p. 35.

${ }^{47}$ Ibid., p. 36.

${ }^{48}$ Konberg, op. cit., p. 100.

${ }^{49}$ Ibid., p. 100. 
del antisemitismo procedía de los problemas sociales achacados a los ricos -entre los cuales se encontraban algunos prominentes judíos-, durante 1893 se decidió escribir artículos en donde hacía varias propuestas para solucionar la cuestión social; ${ }^{50} \sin$ embargo -y como era de esperar- sus esfuerzos sirvieron de poco. Incluso el partido liberal austríaco - defensor tradicional del pueblo de Abraham-dejó de denunciar los actos de antisemitismo cada vez más frecuentes. ${ }^{51}$ Era necesario buscar otros caminos.

Al inicio de 1893 fue invitado a escribir en la revista Asociación de Viena para la defensa ante el antisemitismo. Rechazó la oferta por considerarla insuficiente, creía que era necesario algo con más trascendencia. Se propuso varios planes, entre los que se encontraba la conversión de los austríacos al cristianismo. Así escribió: "Me gustaría llegar hasta el Papa....y decirle: ayúdanos contra los antisemitas y empezaré un gran movimiento a favor de la libre y honorable conversión de los judíos al cristianismo." ${ }^{\circ 2}$ Envió una carta a Leintenberger, presidente de la Asociación de Viena para la Defensa ante el Antisemitismo, quien la consideró una locura y se la enseñó a Nothangel -ferviente católico y también miembro de la Asociación-; éste se horrorizó por la propuesta.

La conversión, según deseaba Herzl, debía hacerse a la luz del día 'con procesiones festivas' ante la catedral de Viena. Sería sellada en una histórica alianza con el Papa pidiendo a la Iglesia que erradicara el antisemitismo. Pero la conversión la harían los hijos no los padres, quienes se quedarían fuera de la catedral; de esta manera, la última generación de judíos mantendría su honor y la siguiente quedaría totalmente asimilada. A cambio, propondría a los editores de su periódico, el Neue Freie Press, tener una política editorial favorable al Papa. La idea de Herzl se basaba en la creencia de que la conversión individual no servía, ya que no cambiaba la percepción de los judíos -se entendería como cobardía-, debía ser colectiva; así los judíos no actuarían como

${ }^{50}$ Ibid., p. 102.

${ }^{51}$ Ibid., p. 108-7.

52 Ibid., p. 115. 
individuos sino como comunidad ${ }^{53}$ y se percibiría como un noble propósito y no como una huida.

Pero la conversión masiva hacia el cristianismo no fue la única opción herzeliana para solucionar de una vez por todas la discriminación. Herzl sabía que los socialistas despreciaban cualquier tipo de distintivo, entre ellos el del judaísmo. Teniendo en cuenta el elevado número de judíos en esa tendencia, Herzl vio una salida al problema. Los judíos, parias en la sociedad europea, se unirían a otros parias para cambiar la sociedad. Al proponer el ingreso en el socialismo, Herzl pensaba que al igual que el proletariado, que había llegado al límite de la deshumanización, los judíos podrían a través de un acto radical transformarse ellos mismos. ${ }^{54}$ No sólo se trataba de la asimilación sino de la recuperación del propio honor -perdido según Herzl por siglos de opresión cristiana-mediante la lucha contra la clase capitalista. Si el estado socialista se conseguía, todo tipo de discriminación desaparecería ya que en él, teóricamente, todos serían iguales y no se distinguirían los ricos de los pobres ni los gentiles de los judíos, por la sencilla razón de que ese tipo de categorías habría desaparecido.

Una tercera solución fue la del duelo, al que era afecto -se intentó batir tres veces-,$-{ }^{55}$ muy al gusto de los miembros de las sociedades estudiantiles de las ciudades germánicas. ${ }^{56}$ Su idea procedía del duelo que tuvo lugar en Francia en 1892 entre el Marqués de Mores y un oficial francés judío. El oficial -aunque lisiado de un brazo- al ser insultado, retó al marqués a duelo con espada. Murió el oficial pero fue considerado como un héroe incluso por el propio Marqués de Mores; al funeral fueron unos cien mil parisinos, el ejército le rindió honores, el secretario de Guerra dijo que la armada no reconocía diferencia entre sus soldados, y los periódicos criticaron el antisemitismo. De esta forma proponía trasladar el caso francés a Austria mediante un duelo con algún prominente antisemita-Barón Von Liechtenstein,

${ }^{53}$ Ibid., p. 115-20.

${ }^{54}$ Ibid., p. 120-4.

${ }^{55}$ Ibid., p. 68-9.

${ }^{56}$ Zweig, op. cit., p. 130-1. 
Georg von Schönerer o Karl Lueger. Se puede suponer que el representante del pueblo judío sería el mismo Herzl; así pretendía devolver el honor al pueblo judío para acabar con el antisemitismo en Austria. ${ }^{57}$

El antisemitismo creciente estaba provocando una grave crisis intelectual en Herzl, quien sin embargo no cambió su visión del pueblo judío de los últimos diez años. ${ }^{58}$ Escribía a su amigo Moriz Benedikt en diciembre de 1892: "un pueblo envilecido a través de la opresión, castrado, atento al dinero, domado en numerosos corrales". E incluso seguía pensando que el antisemitismo era comprensible debido a los defectos de los judíos: "Creo - escribiría- que entiendo el antisemitismo... Lo veo desde el punto de vista de un judío, pero sin odio y sin miedo". Lo entendía como una autodefensa de los gentiles. ${ }^{59}$ Pero si su visión de su propio pueblo no había cambiado, algo había cambiado; a partir de esas fechas empezaría a predicar la necesidad de que el judío pudiera volver a recuperar su orgullo. ${ }^{60}$ El pueblo judío tenía graves defectos -según Herzl- pero no por eso había que dejarlo a su suerte apartándose de él; era necesario regenerarlo. La recuperación de la autoestima sería la que lo redimiría y, una vez conseguida, sería respetado por el resto de las naciones. ${ }^{61}$

En 1894 escribiría su novela El nuevo gueto donde expresaría sus sentimientos de frustración y de haber llegado a un callejón sin salida, tan típico entre tantos de aquellos judíos triunfadores y emancipados de la clase media. ${ }^{62}$ Tras súbita inspiración la escribió de corrido. Redactaría en torno al primer esbozo de la novela: "Escribí totalmente inmerso en ella, de un tirón, mientras reía y lloraba." ${ }^{\text {"E3 }}$ El protagonista de la novela es Jacob, quien cuenta entre sus grandes traumas el no

${ }^{57}$ Konberg, op. cit., p. 125.

58 Ibid., p. 127.

${ }^{59}$ Shimoni, op. cit., p. 91.

${ }^{60}$ Konberg, op. cit.

${ }^{61}$ Ibid., p. 129.

${ }^{62}$ Shlomo Avineri, La idea sionista: notas sobre el pensamiento nacional judio, 1983 , Jerusalén, La Semana Publicaciones Ltda., p. 109, trad. Emilio Abraham.

${ }^{63}$ Konberg, op. cit., p. 130. 
haberse podido batir en duelo con un gentil, ya que justo después de haberse comprometido a hacerlo su padre cayó gravemente enfermo. Este hecho lo corroe por la sensación de haber quedado como un cobarde. Otro de los grandes sufrimientos de Jacob sería la pérdida de la amistad de Franz, un gentil a quien admiraba e imitaba. Franz, ante la entrada en política le pedirá cortar con su amistad por los posibles perjuicios que le ocasionaría el ser visto con un judío. Y es ahí en donde el asimilado Jacob se da cuenta de que sigue estando en el gueto. Además, Jacob sería acusado de traición por aquél con el que se había retado a duelo tiempo atrás. Entonces Jacob retará a duelo a su antiguo enemigo y se hará presente para morir en el mismo. La explicación para Konberg ${ }^{64}$ es clara: Jacob es el mismo Herzl quien hizo todos los esfuerzos por asimilarse -también se batió varias veces como dijimospero siempre sería rechazado porque lo único que hizo fue imitar a la sociedad gentil, a la vez que le faltó coraje; Jacob sigue inmerso en su propio gueto ya que no ha conseguido la estima de los gentiles por faltarle autoestima; así diría Jacob: "Los muros visibles deben ser destruidos desde fuera - pero debemos derribar las barreras invisibles dentro de nosotros mismos. Nosotros mismos! Fuera, debemos romperlos hacia fuera!" La novela termina con un significativo: "Judíos, mis hermanos, no les dejarán vivir de nuevo hasta que aprendan como se debe morir... ¡Quiero salir! ¡Salir del gueto!” Así la autoredención precede a la redención procedente del exterior. Con la aceptación del duelo y la muerte, Jacob se reconcilia consigo mismo: pudo ser valiente; entre los espasmos de la muerte, Jacob tiende la mano a su enemigo: símbolo de que una vez el judío reconciliado consigo mismo sí puede reconciliarse con el mundo gentil en igualdad de condiciones, no como una concesión.

La novela no fue fácilmente aceptada por judíos ni por gentiles. ${ }^{65}$ Herzl la terminó el 8 de noviembre de 1894 y pidió ayuda a su amigo y dramaturgo Arthur Schnitzler a quien envió una copia con una nota

${ }^{64}$ Jacques Kornberg, "Theodor Herlz: a Reevaluation", The Journal of Modern History, 52, 2, 1980. p. 130-48.

${ }^{65}$ Ibid., p. 152-8. 
que demostraba la ambigüedad de Herzl hacia su propia obra y expresaba su propia lucha interior: "Junto con el apasionado deseo de comunicar mi obra al mundo, tengo el sentimiento apasionado de esconderme y enterrarme a mí mismo. Puede ser orgullo, cobardía o vergüenza o lo que quieras." Le desagradaba que se conociera su defensa de la causa judía, por lo que también le escribió que deseaba "esconder los genitales más que en ningún otro momento". Según Konberg, su circuncisión todavía le provocaba vergüenza y vulnerabilidad. Herzl le pidió a su amigo que la presentara a distintos teatros pero sin dar su nombre. Ante el fracaso en Berlín y Viena, Schnitzler le aconsejó firmarla, ya que era un dramaturgo reconocido y eso ayudaría a la obra. En noviembre aceptó que se reconociera su autoría. Herzl estaba rompiendo los puentes; para ese momento ya había dado una conferencia en el Club de los Macabeos de Londres.

Schnitzler le ayudó por amistad pero no estuvo de acuerdo con la obra; le parecía excesivo que Jacob tuviera que morir para redimirse; tampoco creía que todos los judíos fueran cobardes y tímidos; es más, entendía que los gentiles odiaban más a los valientes que a los pusilánimes. Es decir, disentía acerca del origen del antisemitismo: no se les odiaba por ser pusilánimes -como pensaba Herzl- sino simplemente por el hecho de ser judíos. A Schnitzler le hubiera gustado que incluyera a un judío, perteneciente a alguna sociedad estudiantil, que se hubiera batido treinta veces y hubiera sido expulsado de la misma por el hecho de ser judío; y también a algún cristiano que se negara a batirse a causa de su fe para demostrar que el no batirse no era visto por todos como símbolo de cobardía. Claramente a Schnitzler le hubiera gustado una obra distinta.

La obra fue rechazada tanto por judíos como por cristianos. Finalmente se estrenó en 1897 cuando Herzl ya era una figura conocida y los judíos entendieron mejor el concepto de judío regenerado que les quería transmitir. Además para ese momento ya había atemperado algunas de las características más infamantes en los personajes judíos de la obra. 


\section{Herzl y el sionismo: El Estado judío y Altneuland}

A partir de los años ochenta del siglo XIX - después de los pogromos desatados en Rusia- surgieron grupos ideológicos que propugnaban la vuelta de los judíos a Israel. El más activo de ellos fue Hibbat Zion -los Amantes de Sión-, quienes estaban promoviendo el asentamiento paulatino en Palestina gracias al apoyo de Rothschild. Desde ese momento es posible trazar un línea -cada vez más ramificada- de ideologías nacionalistas buscando la vuelta a la Tierra Prometida. Esos movimientos fueron conocidos como sionistas. Bajo esa ideología subyacía la idea de que los judíos eran un pueblo con características peculiares que iban mucho más allá de las religiosas. Estas diversas ideologías tenían en común tres dimensiones: el diagnóstico de una situación dramática de los judíos en tierras de gentiles; la búsqueda de una solución y, finalmente, propuestas de los medios para alcanzar esa solución. ${ }^{66}$ Shimoni, ${ }^{67}$ pedagógicamente, dividió las soluciones en dos grandes grupos: la funcional, que pedía la unión de los judíos para luchar vía diplomática por la Tierra Santa -es decir, conseguir un Estado antes de promover la emigración masiva- y la orgánica, que buscaba la regeneración desde dentro para fomentar la identidad cultural -y entre sus medios para conseguirlo estarían los progresivos asentamientos en Palestina. Los mayores representantes de estas dos líneas serían Herzl para la funcional y Asher Ginzberg -alias Ahad Ha'ampara la orgánica, quien sería el mayor oponente a Herzl dentro del sionismo.

Cuando Herzl fundó la Organización Sionista, en 1897, el concepto sionista se había fijado: era el movimiento político que reuniría los esfuerzos para llevar a todos los judíos que quisieran a Israel -lo que se conoce como hacer aliyah-. Sin embargo no fue él el padre del término sino Birnbaum, quien siete años antes a través de las columnas de Autoemancipación dio luz al concepto y a la palabra. El térmi-

\footnotetext{
${ }^{66}$ Shimoni, op. cit., p. 85.

${ }^{67}$ Ibid., p. 86-7.
} 
no sionismo empezó a sustituir al de nacionalismo judío. A partir de 1893 la revista Autoemancipación dejó de denominarse el órgano del nacionalismo judío para tomar el sobrenombre de 'órgano de los sionistas'.

Sin embargo Herzl no conocía mucho más de cuestiones semánticas que de lo que sabía sobre quienes escribieron acerca de las formulaciones ideológicas y programáticas que le habían precedido. ${ }^{68}$ Alejado como había estado del mundo cultural del judaísmo era "completamente ignorante de los otros a quienes tenía perplejos el mismo problema"69 -como eran las obras de Pinsker - Autoemancipación-o la monumental obra de Hess, Historia de los judios -como tampoco conocía a los Amantes de Sión. Desconectado de ese mundo, las ideas de Herzl no fueron originales ${ }^{70}-\mathrm{y}$ difícilmente podía saber que no lo eran-y algunas de ellas -según Chaim Weizmann, ${ }^{71}$ unos de sus colaboradores, $\mathrm{y}$ primer presidente del Estado de Israel- 'pecaban de simplicidad', eran 'planes increíblemente ingenuos' o 'eran absolutamente irrealizables'. A pesar de ello lo que se llamaría sionismo político hasta el día de hoy es el sionismo que Herzl expuso en su folleto El Estado judío publicado en 1896.

Parece que Herzl elaboró esta idea de un Estado judío como algo posible en mayo o quizá finales de abril de $1895,{ }^{72}$ sin embargo la había concebido dos veces antes, al inicio de 1893 y en octubre de 1894, algunos días antes de la iluminación de El nuevo gueto, pero en ambos casos la rechazó, ya que pensaba que los judíos tenían poco en común aparte de la opresión. Es posible que la victoria del antisemita Lueger en las elecciones para la Curia de Viena le hiciera dar el salto. ${ }^{73}$

${ }^{68}$ Ibid., p. 88.

${ }^{69}$ Chaim Weizmann, Prólogo, en Theodor Herzl, El Estado judio, 1946, Washington, Departamento Latino Americano de la Agencia Judía, p. 5.

${ }^{70}$ Avineri, La Idea Sionista..., op. cit., p. 105.

${ }^{71}$ Weizmann, p. 5-6.

${ }^{72}$ Kornberg, "Theodor Herlz....", op. cit., p. 159.

${ }^{73}$ Ibid.,. p. 159. Lueger fue elegido en mayo de 1895 en minoría, dimitió para ser elegido por mayoría en septiembre. 
Para finales de mayo escribió algunas notas preparatorias para presentarlas al barón de Hirsch ${ }^{74}$-filántropo judío que estaba financiando colonias judías en Argentina. En ellas todavía seguía pensando en la asimilación y propuso al Barón la posibilidad de que los judíos vivieran en una especie de estado subrogado -dentro de alguno de los Estados europeos- en donde se premiarían los hechos heroicos, físicos o morales; gracias a esos estímulos los judíos recuperarían su autoestima y por lo tanto la de los gentiles. Si los judíos respondían, entonces no haría falta irse de Europa. Tampoco rechazó en este momento los matrimonios mixtos, siendo educados los hijos en la fe mayoritaria: le proponía al Barón que diera incentivos económicos para los que lo quisieran hacer; y también seguía pensando en hacer un pacto con el Papa, el Zar y el Kaiser para que, a cambio de la conversión a las respectivas religiones mayoritarias, lucharan contra el antisemitismo. Pero pronto adoptaría posiciones más radicales con el fin de acabar de una vez por todas con el llamado 'problema judío'.

A principio de junio la idea del Estado judío se había posesionado de su mente mientras trabajaba o caminaba hasta el punto que llegó a pensar que iba a enfermar mentalmente: ${ }^{75}$

Durante días y semanas me ha saturado hasta los límites de mi consciencia; la llevo a donde voy, me ronda en mis charlas cotidianas, me atisba por encima de mis hombros de mi pequeño trabajo de periodista; me abruma y me intoxica.

Había encontrado una nueva forma de asimilación: el Estado judío reemplazaría al bautismo, al socialismo o al duelo de honor. Estos parecían ahora a Herzl pequeñas soluciones. A partir de ese momento se resolvería la cuestión entre el asimilacionismo y el judaísmo, porque ambos serían lo mismo ${ }^{76}$ (el pueblo judío se habría asimilado ya que tendría un estado como el resto de los pueblos, sería un Estado

${ }^{74}$ Konberg, Theodor Herzl: from Assimilation, op. cit., p. 160.

${ }^{75}$ Lowenthal, op. cit., p. 3.

${ }^{76}$ Konberg, ibid., p. 160. 
más y el judío un ciudadano más, igual al francés, al alemán....). A través del sionismo Herzl resolvía su ambivalencia con respecto a su judaísmo y a su deseo de asimilación. Un conflicto que le llegaba hasta lo más profundo. ${ }^{77}$ Finalmente, a través del Estado los judíos podrían realizar las metas de la emancipación y la asimilación por ellos mismos, superar sus defectos, quitarse el estigma, ganar en orgullo de ser lo que eran, convertirse en sus propios dueños y al mismo tiempo ganar la aceptación de los gentiles. Este trabajo le dio a Herzl el sentido de misión, la fuente de su carisma como líder. ${ }^{78}$ Hacia la mitad de enero de 1896 hubo algunos editores judíos que se negaron a publicar El Estado judio, que finalmente vio la luz en febrero de ese año.

En el prefacio dejaba claro que las propuestas no eran otra novela utópica al estilo de las ya publicadas: "En primer lugar es menester que defienda mi proyecto contra la calificación de utopía. Sólo prevengo, de esta manera, a los críticos superficiales, de cometer una necedad...", 79 aunque sabía que, tanto él como los que le siguieran en el primer momento, no lo verían realizado: "los que inician este movimiento difícilmente verán su glorioso fin" ${ }^{80}$ Pero al fin ese proyecto se realizaría ya que "El Estado judío es una necesidad universal; por consiguiente surgirá." 81

Tras hablar de los orígenes del antisemitismo y expresar que seguiría existiendo "mientras no se resuelva por medios políticos", 82 propone un plan 'sencillo': se les daría una porción de territorio Palestina o Argentina-y los judíos se encargarían de crear una figura moral, la Society of Jews, ${ }^{83}$ y una persona jurídica financiera, la Jewish Company. ${ }^{84}$ La Society of Jews se encargaría de diseñar los proyectos y

${ }^{77}$ Ibid., p. 160.

${ }^{78}$ Ibid., p. 161.

${ }^{79}$ Herzl, op. cit., p. 13.

${ }^{80}$ Ibid., p. 14.

${ }^{81}$ Ibid., p. 15.

${ }^{82}$ Ibid., p. 19.

${ }^{83}$ En el original.

${ }^{84}$ En el original. 
sería la representante legal ante los gobiernos y la Jewish Company sería la empresa que llevaría a cabo la parte práctica. El estado no sería teocrático, ni el hebreo sería el lenguaje oficial: “¿Quién de nosotros sabe bastante hebreo como para pedir un billete de tren?" Lo que propone es un idioma al estilo de Suiza, en donde cada uno conservaría el suyo y predominará entre todos el más útil sin violencia.

La creación de ese estado sería beneficioso para todos. En el país que se asienten, la Society of Jews podría cargar en parte con las deudas públicas y construir vías de comunicación, entre otras muchas cosas. ${ }^{85}$ En el caso de elegir Palestina, se sanearían las finanzas de Turquía y "para Europa formaríamos allí parte integrante del baluarte contra Asia: constituiríamos la vanguardia de la cultura en su lucha contra la barbarie". ${ }^{86}$ Inmerso en el ambiente colonial de la época e influido por las colonización holandesas e inglesas, Herzl proponía ser una avanzada del mundo occidental en Oriente. ${ }^{87}$ La emigración de los judíos también beneficiaría a los mismos correligionarios que no quisieran dejar sus patrias de origen, especialmente a los pudientes, ya que se liberarían de "la competencia molesta, incalculable e inimitable, del proletariado judío". ${ }^{88}$ Los gentiles también saldrían beneficiados al acabar la competencia en los puestos de profesiones liberales, lo que llevaría al fin del antisemitismo: ${ }^{89}$

Después del éxodo de los judíos, no hay dificultades económicas ni crisis ni persecuciones, sino que comienza un período de prosperidad para los países abandonados. Se inicia un movimiento interno de los ciudadanos cristianos hacia las posesiones abandonadas por los judíos. La emigración se realiza gradualmente, sin perturbaciones, y ya su comienzo significa el fin del antisemitismo.

${ }^{85}$ Herzl, op. cit., p. 39.

${ }^{86}$ Ibid., p. 40.

87 Walid Khalidi, "The Jewish-Ottoman Land Company: Herzl's Blueprint for the Colonization of Palestine", Journal of Palestine Studies, vol. XXII, no. 2, Winter 1993, p. 31.

${ }^{88}$ Herzl, op. cit., p. 24.

${ }^{89}$ Ibid., p. 26. 
Como afirma Konberg, ${ }^{90}$ Herzl cuando escribe el Estado judio sigue viendo al judaísmo con los ojos del antisemitismo austriaco basado en la crítica al enorme poder económico de los judíos. Ya que Herzl entendía, de forma ingenua, que el traspaso amistoso de los bienes de los judíos a manos de los gentiles bastaría para acabar con las miserias de los austríacos. Los países también recibirían el beneficio del comercio, pues los judíos en su nuevo estado necesitarán muchas cosas para iniciar su nueva vida. ${ }^{91}$ Pero el beneficio por antonomasia sería el social: "El descontento social podría ser calmado por un espacio de tiempo que duraría, tal vez, viente años, tal vez más...". 92

\section{La recepción de la idea del Estado judío}

El folleto fue como una bomba. Muchos lo animaron y otros lo criticaron duramente. El rabino Adler entendía que la propuesta era impráctica y además peligrosa. ${ }^{93}$ Asimismo la consideraban en su propio periódico; al burlarse un compañero de un artículo suyo acerca del Estado judio impreso en inglés en el Jewish Cronicle, aparecido poco antes del libro, Herzl le contestó que también podría burlarse de él ácidamente. Su compañero le respondió: "La broma ácida es la publicación del artículo. Si el artículo del Jewish Cronicle aparece en alemán los antisemitas harán buen trabajo con él. Les vendrá muy bien." "94 Y Moritz Benedik, el magnate que financiaba al Neue Freie Presse, le advirtió molesto: "Ningún individuo tiene derecho a asumir la tremenda responsabilidad moral de desencadenar esta avalancha. Todos perderemos nuestra patria actual antes de conseguir un estado judío."95 Moritz le pidió que el libro no se publicara. De la misma manera Hermann Cohen

\footnotetext{
${ }^{90}$ Konberg, Theodor Herzl: from Assimilation, op. cit., p. 80.

${ }^{91}$ Herzl, op. cit., p. 97.

92 Ibid., 98.

${ }^{93}$ Lowenthal, op. cit., p. 88.

${ }^{94}$ Ibid., p. 88.

95 Johnson, La historia de... p. 404.
} 
y Ludwig Geiger, miembros de la intelectualidad judía alemana, consideraban las ideas de Herzl "tan llenas de peligros para el espíritu alemán como la socialdemocracia y el ultramontanismo" "96 y Lucien Wolf, secretario del Joint Foreign Commitee of the Anglo-Jewish Association las consideraba una traición y una provocación al antisemitismo. ${ }^{97}$ Edmond de Rothschild, de la rama francesa de la familia de banqueros, tampoco lo recibió especialmente bien; consideraba sus proyectos no sólo como irrealizables sino también peligrosos ya que su plan ponía en duda el patriotismo de los judíos, ${ }^{98} \mathrm{y}$, lo que fue peor, dio conocimiento público de su rechazo. ${ }^{99}$

Pero no todo fueron críticas; poco a poco se fue haciendo con un buen número de adeptos. A la de Max Nordau, uno de sus más fieles aliados, que conoció a finales de 1895 en Londres, se le fueron sumando otros. También contaría con el apoyo de Israel Zangwill, presidente de la Asociación de los Antiguos Macabeos ${ }^{100}$ y el del coronel Goldsmid un cristiano sionista inglés. Algún rabino lo consideraba el Mesías; los Amantes de Sión de Viena le animaron para que llevara a cabo su proyecto $^{101}$-aunque en general ese movimiento extendido por toda Europa se opondría a Herzl-; también se ganaría la confianza del rabino de Viena Guedemann. Lo cierto es que Herzl, después de la publicación de su obra no pasó desapercibido, y gracias a amigos y enemigos pronto se convertiría en una figura pública.

${ }^{96}$ Howard Morley Sachar, A History of Israel : From the Rise of Zionism to our Time (New York: Alfred A. Knopf, INC, 1998), p. 52.

${ }^{97}$ Idem.

${ }^{98}$ Lowenthal, op. cit., p. 131.

${ }^{99}$ Es posible que Lord Rothschild lo hiciera para evitar cualquier tipo de antisemitismo contra su persona. Lo cierto es que destruyó todos sus papeles con respecto a su labor en Palestina, Cfr. Jean-Christophe, Esther Benbassa Attias, Israel, La tierra y lo sagrado, 2001, Barcelona, Riopiedras, p. 163.

${ }^{100}$ Quizá la frase más conocida de Israel Zangwill fue la de Palestina es "una tierra sin pueblo para un pueblo sin tierra". Cfr. 'The Return to Palestine', New Liberal Review,II, Dec. 1901, p.627 citado en http://www.dutchpal.com/pal/history-03.html. Visitado el 20 de marzo de 2004.

${ }^{101}$ The Jewish Agency for Israel: Departament for Jewish Zionist Education, Timeline, http://www.jafi.org.il/education/herzl/timeline6.html, (consultado 17 febrero 2004). 


\section{Altneuland}

La visión que tenía Herzl acerca del futuro Estado la completó cara al público en su novela de 1902 Altneuland $^{102}$-Nueva vieja tierra. En 1898 estuvo en Palestina y a su vuelta decidió escribir la novela. La obra relata el viaje de un millonario vienés, Kingscourt, en compañía de un judío, Federico Loewenberg, hacia una isla desierta del Pacífico en donde vivirían durante veinte años. El viaje se iniciaría en 1901. Antes de llegar a la isla, Kingscourt se empeñaría en ver Palestina a pesar de las protestas de su amigo judío. La percepción de esa tierra por parte de los dos viajeros fue desoladora -reflejando así lo propios sentimientos de Herzl en su corta visita a Tierra santa. Al cabo de veinte años -1923- la pareja de aventureros volvería a pasar por Palestina. Todo había cambiado: una sociedad cosmopolita los recibía. Se había convertido en una sociedad completamente occidental en donde ninguno de los avances de la técnica faltaban. Allí se hablaban todo tipo de lenguas y practicaban todo tipo de religiones. En donde hubo poblachos miserables ahora había villas perfectamente trazadas; la Ciudad vieja estaba dedicada exclusivamente al turismo y el mal olor y la miseria de antaño había desaparecido. Y sobre la explanada del Templo se levantaba-ipor fin!- el Templo a imagen del de Salomón, destruido en el año 70 d.C. por Tito. ${ }^{103}$ Ese era el sueño de Herzl: una sociedad occidental y laica tal y como la había descrito en el Estado judío en donde todos convivirían pacíficamente.

\section{¿Y los árabes de Palestina?}

Sin embargo hay un pequeño problema que ni en El Estado judío ni en Altneuland queda resuelto. ¿Cómo había que tratar a los árabes que

${ }^{102}$ Se puede ver un resumen y análisis en Muhammad Ali Khalidi, op. cit., y en Jeremy Stolow, "Utopia and Geopolitics in Theodor Herzl's Altneuland", Utopian Studies, 8, 1, 1997.

${ }^{103}$ El Templo de Salomón fue destruido en el siglo VI a.C. y reconstruido poco después del exilio de los judíos en Babilonia. 
habitaban ya esas tierras? ¿Si las villas miserables habían desaparecido en Palestina -como escribe relatando la segunda visita de los aventureros en Altneuland- qué había pasado con los árabes que habitaban en ella? En la novela, los árabes que aparecen están muy agradecidos con los judíos por el enorme progreso que han llevado a Palestina pero no se dice nada de a dónde fueron los habitantes de la Ciudad vieja o de las miserables villas. ${ }^{104}$

En sus diarios Herzl es más explícito con respecto a qué hacer con la población autóctona-aunque no dice si se está refiriendo a Palestina, Argentina o cualquier otro lugar. Allí escribió el 12 de junio de 1895, poco después de iniciarlos: "Cuando ocupemos la tierra aportaremos beneficios inmediatos a la tierra que nos reciba. Debemos expropiar con cuidado la propiedad privada en los territorios que se nos asigne." "105 Para la población que la habite, Herzl escribía ese mismo día: "Intentaremos que la población pobre se esfume a través de las fronteras intentando buscarles trabajo en los países limítrofes a la vez que se le impedirá trabajar en nuestro propio país." ${ }^{106}$ Esa transferencia debería ser de forma discreta: "Tanto el proceso de expropiación como la expulsión de los pobres debe de hacerse de forma discreta y con circunspección. Dejemos que los propietarios de la tierra crean que nos están engañando, vendiéndonos cosas por mayor valor de lo que valen. Nosotros no les vamos a volver a vender nada."107 La compra se haría mediante pagos elevados y sólo a judíos. ${ }^{108}$ Se daba cuenta de que la situación no iba a ser fácil por lo que propone la organización de una

${ }^{104}$ Khalidi entiende que la cuestión acerca de qué hacer con los árabes sólo se toca de forma marginal -sin entrar en detalles- con el fin de no escandalizar a los gentiles -a los que, según Khalidi, estaba destinada la novela más que a los judíos. Cfr. op. cit.

105 Theodor Herzl, The Complete Diaries of Theodor Herzl, V. 1, 1960, New York, Raphael Patai, p. 88, trad. Harry Zohn, en Rabbi Chaim Simons, A Historical Survey of Proposals to Transfer Arabs from Palestine 1895-1945 (Simons, Rabbi Chaim, 1 de enero 20032003 [cited 9 de marzo 2004]); available from http://www.geocities.com/CapitolHill/ Senate/7854/transfer.html.

${ }^{106}$ Herzl, The Complete Diaries..., ibid.

107 Ibid.

${ }^{108}$ Ibid., p. 89. 
compañía que facilitara el pago y el traslado a aquellos que fueran remisos a marcharse, ${ }^{109}$ aunque si no quisieran marcharse no se les haría nada. ${ }^{110}$ Un poco después, entre el verano de 1901 y los inicios de 1902, escribió, con el fin de entregárselo al Sultán, un proyecto acerca de la compañía que se encargaría de la colonización -la Compañía de tierras judeo-otomana- ${ }^{111}$ donde escribiría acerca del intercambio de tierras con los nativos:

El derecho a intercambiar enclaves económicos en el área-con la excepción de los santos lugares- compensando a los propietarios con lotes del mismo tamaño e igual calidad en otras provincias y tierras del Imperio Otomano. Los costos de la emigración deberán ser pagados a los propietarios y deberán recibir un adelanto para que construyan las casas necesarios y los utensilios necesarios.... ${ }^{112}$

Lo que no se atrevió a escribir cara al público lo plasmó diáfanamente en documentos privados. Había que dejar el país libre-cualquiera que fuese- para dar cabida a los emigrantes judíos.

\section{La Organización sionista mundial y el Primer congreso sionista}

Tras varios fracasos en 1895 y 1896 con banqueros y filántropos judíos decidió dirigirse a la población tal como le dijo a Edmond de Rothschild -rico judío y filántropo francés:

Usted era la pieza angular de toda la estrategia [conseguir fondos para convencer al Sultán de que cediera Palestina a los judíos]. Si usted se niega, todo lo que he hecho se rompe en pedazos. Me veré obligado a proceder de una forma distinta. Iniciaré una vasta agitación. ${ }^{113}$

${ }^{109}$ Ibid., p. 90.

${ }^{110}$ Ibid., p. 88.

111 Khalidi, "The Jewish-Ottoman Land Company: Herzl's Blueprint for the Colonization of Palestine", p. 44.

${ }^{112}$ Ibid., p. 30.

${ }^{113}$ Lowenthal, op. cit., p. 187. La entrevista tuvo lugar el 19 de julio de 1896. 
Con ese objetivo iniciaría los preparativos para crear una Organización mundial sionista que sería la encargada de llevar a cabo la magna obra. Sin embargo no lo tenía fácil, los Amantes de Sión de Berlín también estaban en contra de él y deseaban -aunque no la hicieron-una declaración pública en contra de Herzl. ${ }^{114}$ Tras los repetidos fracasos Herzl se encontraba bajo de ánimo: "Debo confesarlo: estoy desmoralizado", escribía el 13 de octubre; "de ninguna parte ayuda; desde todos los flancos ataques...". Además corrían rumores de que su proyecto tenía intereses económicos de acuerdo con una compañía colonizadora inglesa. ${ }^{115}$ Hacia diciembre estaba al límite de sus fuerzas: "Siento que estoy cada vez más agotado. Más a menudo que nunca creo que mi momento está llegando a su fin. A la vez estoy totalmente convencido de su viabilidad, pero no puedo superar las dificultades iniciales."

Para enero de 1897 pareciera que recuperaba la esperanza y se disponía a crear un periódico: "Con un millón podríamos crear un gran periódico. Y los gobiernos negocian con los grandes periódicos como un poder en frente de otro." $" 117$ Su ánimo se iba levantando ante la respuesta de muchos: "El sionismo está ganando la estima de la gente sencilla en todo tipo de países. La gente está empezando a tomarnos seriamente." Mientras tanto preparaba con ahínco el Primer congreso sionista.

Con muchas dificultades -y un solo anuncio, el de un mercader de telas- a inicios de junio apareció Die Welt, ${ }^{118}$ su periódico destinado a difundir el sionismo; pero seguían las malas noticias, el 8 de junio los Amantes de Sión ingleses -entre cuyos dirigentes estaba su amigo el Coronel Goldsmid-, se negaban a enviar delegados al Primer Congreso Sionista y, lo peor, lo publicaron en la prensa. ${ }^{119}$

\footnotetext{
${ }^{114}$ Ibid., p. 195.

115 Ibid., p. 199.

116 Ibid., p. 200.

117 Ibid., p. 201.

118 Ibid., p. 212.

${ }^{119}$ Ibid., p. 213.
} 
A pesar de las grandes dificultades el Congreso se celebró entre el 29 y 31 de agosto en Basilea. Fueron 197 delegados de quince países -incluyendo Estados Unidos, Palestina y Argelia; el resto europeos. En la mayoría de los casos eran representantes de los Amantes de Sión ${ }^{120}$ de esos países, en otros se representaban a sí mismos. Entre telegramas y cartas el congreso recibió decenas de miles en donde se declaraba la disposición a emigrar -50.000 procedían de Rumanía, 10.000 de Galitzia.

El temor al fracaso estaba en el ambiente y el mismo Herzl lo veía e, incluso, pensó, en olvidarse de su sueño si el congreso fracasaba, y limitarse a seguir con Die Welt. ${ }^{121}$ Poco antes de iniciarse el congreso recapitulaba las dificultades con las que se tendría que encontrar en él y sobre las que debía ser especialmente cuidadoso: el periódico para el que trabajaba -el Neue Freie Press-al que no debía comprometer; las diferencias entre ortodoxos y modernistas; los patriotas austríacos; los turcos y el Sultán a los que no debían llegar noticias alarmantes; el gobierno ruso al que no debía herir, aunque la deplorable situación de los judíos se debía nombrar; los cristianos y su preocupación por los santos lugares; Edmond de Rothschild; los Amantes de Sión; los colonos palestinos a quienes no se podía comprometer mucho para no quitarles el favor de Rothschild; y finalmente las debilidades humanas: las diferencias personales, los celos y las envidias. Ante esto concluía: "Debo conducir el movimiento de forma impersonal, y no permitir que se me vaya de las manos. Es una labor hercúlea -sin exagerar."122 Herzl debió sentirse seguro y pensar que había superado las pruebas griegas ya que de regresó a Viena totalmente agotado escribió el párrafo profético quizá más citado del sionismo: ${ }^{123}$

${ }^{120}$ En la mayoría de los casos los Amantes de Sión tenían una visión contraria a la de Herzl, preferían colonizar poco a poco con la ayuda de filántropos, pero vieron en el Congreso la oportunidad de difundir su movimiento a la vez la posibilidad de dirigirlo hacia sus propios intereses.

${ }^{121}$ Lowenthal, op. cit., p. 220.

122 Ibid., p. 221-2.

123 Ibid., p. 224. 
Si tuviera que resumir el Congreso en una palabra - de la que tendré cuidado de no publicar- sería ésta: en Basilea fundé el Estado judío. Si dijera esto en voz alta sería aclamado con una universal carcajada. En cinco años quizás, y con seguridad en cincuenta años, todo el mundo lo sabrá.

El resultado exitoso del evento le confirmó que los judíos eran algo más que la suma de una serie de rasgos culturales comunes, eran un pueblo: ${ }^{124}$

El sionismo ha conseguido algo notable hasta ahora visto como imposible: la unión entre los elementos del judaísmo ultramodernos y los ultraconservadores. El hecho de que se haya conseguido sin humillantes concesiones por ambas partes, sin sacrificios intelectuales, es una prueba más, si esa prueba fuera necesaria, de la entidad nacional de los judíos. Una unión de esta clase sólo es posible con una base nacional.

El Primer congreso ya se había realizado alcanzando una enorme publicidad. Ahora hacía falta conseguir el dinero; crear un banco. Los banqueros judíos no quisieron apoyarlo por lo que se decidió por las masas y en una conferencia en abril de 1898, preparando el Segundo congreso sionista, describía a los sionistas como los soldados de la Revolución Francesa que se lanzaron a la guerra sin zapatos ni calcetines. ${ }^{125}$ Hacia mayo los preparativos para el banco habían empezado; ahora necesitaba que los poderosos de la tierra lo apoyaran.

\section{La diplomacia}

Si la labor de convencer a sus propios correligionarios de su idea fue 'hercúlea' según propia expresión de Herlz, no fue menos digna del

${ }^{124}$ Ammon Rubinstein, From Herzl to Rabin: The Changing Image of Zionism, 2000, New York, Holmes \& Meier, p. 3.

${ }^{125}$ Lowenthal, p. 230. 
héroe mítico la labor diplomática desempeñada por Herzl en los pocos años que le quedaban de vida. Hacia 1895 Herzl estaba dando el paso definitivo. Ya no le importaba que el mundo supiera su deseo de redimir al pueblo judío. El boceto del Estado judío ya estaba casi terminado y era necesaria una intensa diplomacia de altos vuelos para que la utopía de papel pasara a ser realidad. El dos de junio de 1895, mientras terminaba su obra, consiguió por fin la entrevista con el barón de Hirsch. La cita tenía como objetivo convencer al barón que su filantropía estaba equivocada y que podía hacer mucho más. Herzl, según su propio relato, se presentó perfectamente ataviado, aunque con ropa ya usada para evitar la sensación de advenedizo; ${ }^{126}$ le importaba dar buena impresión, en parte para destruir la imagen del judío del gueto, considerado por él como patético. ${ }^{127}$ La entrevista fue un fracaso total, en parte debido a la arrogancia de Herzl. En una carta escrita al día siguiente le diría: "Usted es el gran judío del dinero; yo soy el judío del espíritu... Naturalmente usted me respondió con una gentil ironía: Así lo esperaba... Así es como las ideas nuevas son recibidas." ${ }^{28}$ Hirsch le pagó con la misma moneda al considerarlo un teórico y un ignorante ${ }^{129}$ e incluso entendió sus ideas como peligrosas según relató el propio Herzl: 'No, no, no, gritó [Hirsch]. Todas nuestras desventuras proceden de que los judíos quieren llegar demasiado alto."130

El tono de la entrevista con Hirsch se repitió en varias ocasiones con otros grandes magnates judíos. Herzl era claro: se le debía apoyar en todo y si no, las relaciones se rompían a no ser que su interlocutor cambiara de opinión. Su visión maximalista le acarreó grandes problemas ya no sólo con los magnates sino incluso con los sionistas convencidos que preferían ser más prudentes. Sin embargo Herzl no se desanimó y el 9 de junio, poco después de su tormentosa reunión con Hirsch, escribía:

\footnotetext{
${ }^{126}$ Ibid., ed. p. 14.

127 Johnson, op. cit., p. 403.

${ }^{128}$ Lowenthal, op. cit., p. 20.

129 Johnson, ibid., p. 403.

${ }^{130}$ Lowenthal, ibid., p. 18.
} 
primero negociaré con el Zar... después con el Kaiser. Después con Austria. Después con Francia... Después lo que la necesidad dicte. Para impresionar en las cortes europeas debo conseguir las máximas condecoraciones. Las inglesas primero. ${ }^{131}$

\section{La diplomacia con el Imperio otomano y el Kaiser}

Aunque es cierto que Herzl en el Estado judio proponía bien Argentina o Palestina, -y también que aceptó más adelante el ofrecimiento de Uganda (en realidad la actual Kenia) por parte del gobierno inglés- lo cierto es que la mayoría de los esfuerzos diplomáticos en su corta vida como sionista fueron encaminados a que el Imperio otomano permitiera a los sionistas crear su Estado judío en Palestina. Para ello intentó encontrar el apoyo de los magnates judíos y de las cancillerías europeas -Berlín, Londres, Viena, Moscú y el Vaticano. La propuesta que Herzl haría al gobierno de la Sublime Puerta era sencilla: ${ }^{132}$ dinero a cambio de un Estado, en principio, dependiente de alguna forma de Constantinopla. La enorme deuda del Imperio otomano favorecía la maniobra. Sin embargo la jugada no era fácil. Para convencer al Sultán tenía que demostrar que tenía el apoyo de los banqueros judíos y para convencer a éstos necesitaba que el Sultán le diera el visto bueno primero, pero como éste no estaba convencido era necesario que las cancillerías europeas presionaran. Pero éstas a su vez solicitaban de Herzl que demostrara que tenía el respaldo de los banqueros. Herzl por su parte esperaba tener el beneplácito de los gobiernos como salvaconducto frente a los remisos banqueros... De tal forma que el círculo no acababa de romperse nunca. Aún así, Herzl luchó hasta el agotamiento y la misma muerte procurando la cuadratura del círculo.

En junio de 1896 consiguió traspasar la Sublime puerta y entrevistarse con altos representantes del Sultán. Herzl tuvo mala suerte; el

${ }^{131}$ Ibid., p. 39.

132 Kalus Polkhen, "Zionism and Kaiser Wilhelm," Journal of Palestine Studies, 4, 2 (1975), p. 76. 
Sultán estaba enfermo así fue que en la espera aprovechó para ver a Yakovlev, embajador ruso en Constantinopla, en donde le planteó sus ideas y su deseo de ver al Zar para pedirle que le apoyara ante el Sultán. ${ }^{133}$ Después de esa visita se dirigió hacia la Sublime Puerta en donde logró una visita al Gran Visir - Khalil Rifat Pasha- de la que no sacó tampoco muy buena impresión, ya que no sólo parecía que a aquél le disgustaba la idea sino que también desconfiaba de ella. ${ }^{134}$ También pudo hablar con personas de la Secretaría de relaciones exteriores, entre ellas uno de sus más altos consejeros, Daoud Effendi, judío, quien le desanimó: "Habría enormes dificultades; en realidad-comentaba Herzl- él consideraba el asunto como imposible." 135 Pero las noticias peores estaban por llegar. Vio a Nevlinski por la noche -su contacto con el Sultán- quien le comunicó ante media botella de champagne -media, en señal de duelo- las palabras de Abdul Hamid II ante su propuesta: ${ }^{136}$

Si el señor Herzl es tu amigo en la misma medida que tú lo eres mío, entonces avísale para que no dé un solo paso más sobre el asunto. No puedo vender ni un pie de mi tierra, porque ella no me pertenece a mí sino a mi pueblo. Ellos conquistaron este Imperio y lo fertilizaron con su sangre. La cubriremos otra vez con nuestra sangre antes de permitir que nos sea quitada... Los judíos pueden ahorrar sus millones. Cuando mi imperio sea dividido, quizás puedan conseguir Palestina a cambio de nada. Pero sólo nuestro cadáver puede ser dividido. Nunca permitiré una vivisección.

Frente a esta negativa, hecha ante varias personas, las posibilidades de que viera al Sultán eran nulas. Por lo menos Herzl pudo enviar sus artículos a Viena en donde relataba la buena acogida por los diplomáticos turcos ${ }^{137}$ con lo que se daba publicidad a sí mismo y a su

\footnotetext{
${ }^{133}$ Lowenthal, op. cit., p. 147-8.

134 Ibid., p. 150.

135 Ibid., p. 151.

136 Ibid., p. 152.

137 Ibid., p. 161.
} 
movimiento: la propuesta de Herzl había llegado a los oídos de las potencias extranjeras, quienes a su vez le preguntaron al Sultán qué pensaba de la propuesta de Herzl. ${ }^{138}$ Aparentemente no había conseguido nada, pero empezaba a darse a conocer en el mundo diplomático.

Herzl preveía esa negativa, por lo que antes de su viaje a Constantinopla intentó contactar al Kaiser como un apoyo frente al Sultán. El gobierno alemán tenía gran interés en aumentar su influencia en Oriente Medio una vez que Inglaterra se descalificaba ante el Imperio otomano a causa de la diplomacia gladstoniana de los derechos humanos. ${ }^{139} \mathrm{El}$ 22 de abril de 1896, ya publicado El Estado judío y antes de su primer viaje a Constantinopla, se entrevistó con el Duque de Baden -tío de Guillermo II- con el fin de que lo introdujera al Kaiser. Su recibimiento fue muy favorable. ${ }^{140}$ A pesar de la buena disposición del Duque la posibilidad de entrevistarse con el Kaiser parecía lejana; partió hacia Constantinopla con las manos vacías. Herzl no se desanimó, la perseverancia quizá fue la virtud más grande que poseía, y tras el Segundo congreso sionista, en agosto de $1898,{ }^{141}$ lo intentó de nuevo. En ese momento ya era bien conocido en el mundo político alemán por lo que las posibilidades de que el Kaiser lo recibiera eran mayores. Además, las esperanzas con el Sultán se reavivaron durante el Segundo congreso: inesperadamente llegó un telegrama del Sultán felicitándolos con motivo del evento; detalle que sorprendió al propio Herzl. ${ }^{142}$ Inmediatamente después del Congreso volvió a ver al Duque de Baden quien lo recibió con gratas noticias: el Kaiser estaba al tanto del sionismo y había encargado a Eulenburg, embajador en ese momento en Viena, para que estudiara el asunto; y le informaba que las disposiciones del Sultán eran favorables al sionismo. ${ }^{143}$ Más no se podía esperar apenas dos años después de haber iniciado su odisea.

${ }^{138}$ Ibid., p. 165.

${ }^{139}$ Charles Zorgbibe, Historia de las relaciones internacionales, 1997, Madrid, Alianza, vol. 1, p. 116-7.

${ }^{140}$ Lowenthal, op. cit., p. 111-25.

${ }^{141}$ En él se decidió la creación del banco que financiaría la emigración a Palestina.

${ }^{142}$ Lowenthal, op. cit., p. 234.

143 Ibid., p. 234. 
Herzl no perdió el tiempo. El 7 de octubre estaba en el castillo de Eulenburg. Las nuevas eran esperanzadoras: el Kaiser estaría de acuerdo con un protectorado siempre que el Sultán accediera a ello. ${ }^{144}$ Herzl estaba encantado; esa solución sería lo mejor que los "fuertes, elevados, morales y bien gobernados alemanes podían hacer por el carácter judío". ${ }^{145}$ La cuestión para Herzl era qué solución sería la más factible, si estar bajo el Sultán o bajo el Kaiser. En cualquier caso, concluía felicitándose ante el buen tenor del Emperador alemán hacia sus proyectos y no dejaba de anotar una frase irónica destinada a los judíos pudientes: "los desgraciados ricachones no podrán mantenerse en su anterior actitud". ${ }^{146}$

El 9 de octubre pudo de nuevo ver al duque de Baden. Lo recibió con gran deferencia y platicaron de las complicaciones políticas con respecto al Estado judío en Palestina. Según el Gran duque, de Rusia se podía esperar cualquier cosa; los ingleses lo aprobarían ya que la Iglesia de Inglaterra lo aprobaba; entendía que Francia era tan débil que no podría oponerse al fait accompli. Y le comunicó la grata noticia de que el Kaiser estaría dispuesto a que la emigración de judíos a Palestina se hiciera bajo su protección. ${ }^{147}$ Herzl salió reconfortado

52 después de meses de trabajo agotador.

La propuesta de Herzl al Kaiser no podía menos que agradarle a este último en su proyecto de Marcha hacia el Este: si un número importante de los 600.000 judíos que vivían en Alemania emigraran a Palestina sería una forma excelente de tener unos lazos culturales y económicos en esa parte del mundo. Así Die Welt, el periódico sionista dirigido por Herzl, en octubre de 1898 exultaba esperando un estado judío bajo protección alemana: "Alemania en el Este llevará a un nuevo florecimiento al pueblo de la antigua Palestina." 148

${ }^{144}$ Ibid., p. 250.
${ }^{145}$ Ibid., p. 252.
${ }^{146}$ Ibid., p. 252.
${ }^{147}$ Ibid., p. $255-6$.
${ }^{148}$ Polkhen, op. cit., p. 79. 
El interés del Kaiser acerca de Medio oriente era grande. Con Bismarck ya se habían realizado algunos contactos en esa zona del mundo -misiones oficiales alemanas en 1882. La Weltpolitik de Guillermo II dispararía las relaciones con el Imperio otomano. El Kaiser inició una serie de contactos que culminarían con su visita oficial a Constantinopla en 1889 -consiguió concesiones de ferrocarriles hacia Ankara y Konia en ese mismo año- ${ }^{149}$ que darían lugar a un tratado de comercio en 1890. En su segunda visita, en 1898, se convertiría en el tutor exclusivo del Imperio otomano ${ }^{150}$-casi desmoronado ante la presión de Rusia e Inglaterra y con una deuda impagable. En ese viaje se concretaría el ambicioso proyecto de la construcción del ferrocarril hasta Bagdad, con el que se pretendía unir Constantinopla con el Golfo Pérsico. ${ }^{151}$ De esta forma también se uniría vía ferrocarril Berlín-Bagdad; el Báltico y el Golfo pérsico.

Precisamente durante ese viaje Herzl pudo ver a Guillermo II. El 18 de octubre tuvo por fin su esperada entrevista. Von Bülow ${ }^{152}$-secretario de Exteriores-, que estuvo con ellos, nunca confió en la capacidad de Herzl en cuanto a la consecución de fondos y lo expresó así. El Kaiser fue más amable y dirigiéndose a Bülow le contestó: "Se puede estar seguro de que impresionará que el Emperador se interese personalmente en el tema." Poco antes de despedirse preguntó a Herzl si quería que le dijera algo al Sultán: "Una Chartered Company ${ }^{153}$ bajo protección alemana"-le contestó. "Bien, una Chartered Company" respondió el Kaiser y se despidió con un fuerte apretón de manos. ${ }^{154}$

El 2 de noviembre vio de nuevo al Kaiser en Jerusalén en una recepción en la que esperaba el visto bueno a los planes expuestos

149 Zorgbibe, op. cit., p. 116.

${ }^{150}$ Ibid., p. 117.

151 Polkhen, ibid., p. 77.

152 Bernard von Bülow fue secretario de Exteriores desde 1897 a 1900 y desde esa fecha hasta 1908 canciller de Alemania -Primer Ministro.

${ }^{153}$ La Chartered Company era una compañía con capital privado y una concesión monopólica estatal usada por el Imperio Británico con fines comerciales y coloniales.

${ }^{154}$ Lowenthal, op. cit., p. 270-2. 
pocos días antes en Constantinopla. ${ }^{155}$ Pero el Kaiser, tal como apuntó Herzl en sus diarios, no dijo ni sí, ni no. A Herzl le pareció que su proyecto estaba perdiendo interés a los ojos del rey prusiano y escribió el día de la partida: 'apenas buenos resultados'. ${ }^{156}$ Aún cuando el Kaiser estaba interesado en tener en Oriente Medio ciudadanos germanófonos no estaba interesado en provocar a su aliado turco. ${ }^{157}$

A la vuelta a Viena escribiría a su protector el duque de Baden: "debo asumir que la esperanza, especialmente querida por mí ha desaparecido, y por lo tanto no podemos obtener nuestro deseo bajo el protectorado alemán. Siento tener que decírselo...". 158

A pesar de las malas noticias Herzl siguió intentándolo y reconoció a sus colaboradores que llevaría a cabo su proyecto solo o bien bajo protección germana o inglesa. ${ }^{159}$ Pronto optaría por Inglaterra.

\section{Herzl y los británicos}

Una vez cerrado el camino alemán ${ }^{160}$ Herzl lo intentaría con Gran Bretaña. Ésta se había hecho con el control efectivo de Egipto a partir de 1882 y controlaba la mayor parte de las acciones del Canal de Suez, y mediante la Caja de la deuda ${ }^{161}$ sometía de hecho al Imperio otomano. La agresiva política del Kaiser hacía peligrar el predominio inglés en la zona y en un momento en el que la corona inglesa necesitaba de

${ }^{155}$ Polkhen, op. cit., p. 292.

${ }^{156}$ Lowenthal, ibid., p. 259.

${ }^{157}$ Polkhen, ibid., p. 80.

${ }^{158}$ Lowenthal, ibid., p. 302.

159 Polkhen, ibid., p. 80.

${ }^{160}$ Aunque Bondenheimer, uno de sus más próximos colaboradores, continuaría intentándolo incluso oponiéndose a Herzl en el caso de Uganda.

${ }^{161}$ La Caja de la Deuda, en la que también participaban otras potencias, se había establecido para asegurarse el pago de la enorme deuda del Imperio Otomano con las potencias europeas. La Caja era la encargada de cobrar un sinfín de impuestos que debería recaudar el Sultán, pero una vez cobrados iban directamente a las arcas de las potencias como pago de la deuda otomana. 
todos los apoyos y estaba saliendo -a su pesar- del espléndido aislamiento, cualquier ayuda era bien recibida. ${ }^{162}$

Herzl, en el discurso inaugural del Cuarto congreso sionista celebrado en Londres, despejó la duda acerca de qué camino tomar: "Inglaterra, libre y poderosa Inglaterra, cuya visión abarca los siete mares, nos entenderá a nosotros y a nuestras aspiraciones. Desde aquí el movimiento sionista alcanzará lejanas y altas cimas." ${ }^{\text {"163 }}$ El resultado de ese congreso quedó resumido gráficamente en sus diarios: ${ }^{164}$

Hubo mucho ruido.. y redoblar de tambores. De 'trabajo', no hubo nada, naturalmente, aún así los resultados fueron excelentes. Nos manifestamos ante el mundo inglés, y nuestra manifestación fue notada. Toda la prensa publicó las cosas que necesitábamos y todavía necesitamos.

El ruido iba haciendo su efecto y en mayo de 1901 pudo ver, por primera y última vez, al Sultán y hablarle del pago de la deuda y del asentamiento judío en Palestina; pero poco consiguió. Pronto se dio cuenta de que no era más que una baraja más en el juego para enfrentarlo a los franceses, ${ }^{165}$ quienes también tenían intereses en la zona. La jugada era sencilla, el Sultán amenazaba a los franceses - quienes seguían presionando para cobrar su deuda-con recurrir a dinero inglés o alemán de procedencia judía, lo que implicaba que, si esa amenaza era cierta, la influencia francesa disminuiría en el Imperio otomano todavía más.

En 1902 publicaría su novela Altneuland y en octubre se encontraba de nuevo en Inglaterra en donde se entrevistó con J. Chamberlain -Secretario de las colonias- quien le dijo que el situar el estado en Palestina o cerca no era posible pero que le buscaría un sitio en alguna

162 Inglaterra había llegado al máximo de su expansión a finales del siglo XIX y ese hecho le había provocado enfrentamientos con Rusia, Francia, Estados Unidos y cada vez más con Alemania. Por eso decidió iniciar una serie de pactos defensivos - 1902 con Japón, 1904 con Francia, 1907 con Rusia- con el fin de frenar al expansionismo alemán.

163 Lowenthal, op. cit., p. 330.

164 Ibid., p. 331.

165 Ibid., p. 359. 
de las colonias inglesas. ${ }^{166}$ Herzl insistió y le señaló en un mapa donde quería tener su Estado -en Al Arish, en la península del Sinaí. Chamberlain cedió al darse cuenta de que era una zona desértica y sin grandes poblaciones alrededor; prometió ayudarle siempre que Lord Cromer -virrey de Egipto- lo apoyara. ${ }^{167}$ Se envió una delegación judía, en la que iba Herzl, a Egipto para inspeccionar el terreno. ${ }^{168} \mathrm{Sin}$ embargo en mayo de 1903 Lord Cromer anunciaba que el gobierno egipcio $^{169}$ se negaba a recibir la emigración judía.

Un mes antes de recibir esa descorazonadora noticia, en abril, Herzl tuvo otra entrevista en Londres con Chamberlain, quien acababa de regresar de África y le anunció con alegría: "He visto una tierra para ustedes en mis viajes recientes...y ésa es Uganda. Está en la costa y el clima es excelente para los europeos...y pensé para mí mismo, allí hay una tierra para el Dr. Herzl, pero claro él solo quiere ir a Palestina o a sus alrededores." ${ }^{\prime 70}$ Aunque a Herzl no le gustó la propuesta, la negativa a Al Arish, recibida poco después, y la matanza de judíos en la Pascua de 1903 en la población rusa de Kishinev le hizo replantearse la oferta -a la vez que seguía intentando presionar al Sultán vía Rusia y buscaba también otras soluciones como Mozambique, con los portugueses, Congo con los belgas o Trípoli con los italianos. ${ }^{171}$

Mientras tanto el gobierno inglés estaba dando pasos acerca de lo de Uganda. Lloyd George era el encargado de ello. La propuesta de Uganda se llevó al Sexto congreso sionista el 26 de agosto de 1903. Herzl expuso que era un paso intermedio en el camino hacia Palestina. Se votó enviar una delegación para investigar. La tensión llegó a tal grado que los que votaron que no, se reunieron en otra sala para llorar. La oposición procedió principalmente de los rusos, quienes le llamaron

166 Ibid., p. 375-6.

167 Ibid., p. 377.

${ }^{168}$ Se puede ver un relato de las peripecias de Egipto en Desmond Stewart, "Herzl's Journeys in Palestine and Egypt," Journal of Palestine Studies, 3, 3 (primavera 1974).

${ }^{169}$ Aunque existía un gobierno autóctono lo cierto es que el verdadero dueño y señor de Egipto era Inglaterra.

${ }^{170}$ Lowenthal, op. cit., p. 383.

171 Ibid., p. 386. 
traidor, ${ }^{172}$ también de parte de Bondenheimer, uno de sus más próximos colaboradores, que lo acompañó en la visita a Constantinopla en la entrevista con el Kaiser y quien pensaba que todavía era posible llegar a Jerusalén pasando por Berlín. ${ }^{173}$ A final del año la opción de Uganda era descartada entre otras cosas por la poca población que podría absorber. ${ }^{174}$ Era necesario empezar de nuevo.

Negociaciones con los rusos, austríacos y el Vaticano

El intento con el Zar - a pesar de la política criminal de éste hacia los judíos- se remontaba a la primera visita de Herzl a Constantinopla en donde se entrevistó con el embajador ruso en esa ciudad. También lo intentó en la Conferencia de Paz celebrada en La Haya en junio de 1900. En ninguna tuvo éxito.

Tras la matanza de Kishinev de 1903 el momento parecía propicio, ya que la opinión pública mundial estaba en contra del Zar por su política contra los judíos. Consiguió una entrevista con el ministro del Interior y con el todopoderoso y antisemita primer ministro Witte. El resultado fue pobre, ya que Herzl deseaba la libre difusión del sionismo en Rusia, que implicaba libertad de reunión, peligrosa en la mentalidad autocrática del gobierno ruso. Según le manifestó Witte, el 50 por cien de los revolucionarios eran judíos, mientras que los ciudadanos rusos de esa religión eran apenas 7 millones de 136 millones de la población total. ${ }^{175} \mathrm{El}$ darles libertad de organización sería un peligro. Además, la intención del Zar era la inculturación de todas las nacionalidades dentro de su vasto imperio, y la difusión del sionismo lo único que conseguiría sería el fomento de la conciencia nacional de los judíos, todo lo contrario a los deseos del Zar. En la conversación con Witte, Herzl contraargumentaba que la organización sionista alejaría a los judíos de los movimientos

${ }^{172}$ Ibid., p. 411-2.

${ }^{173}$ Polkhen, op. cit.

${ }^{174}$ Lowenthal, ibid., p. 408-9.

175 Ibid., p. 395. 
revolucionarios y además el éxodo a Palestina haría que el problema de los judíos en Rusia desapareciera. Sin embargo el resultado fue pobre debido a las tirantes relaciones del Zar en ese momento con el Sultán, por lo que difícilmente San Petersburgo podría presionar para que el Sultán concediera una tierra en Palestina a los judíos. ${ }^{176}$

No tuvo mucha más suerte Herzl en Roma, en Viena o en el Vaticano.

En enero de 1904 se entrevistó con Merri del Val, Secretario de Estado y del Vaticano, y con Pío X a quienes le hizo la misma petición pero sin resultado. ${ }^{177}$

El rey de Italia aparentaba tener mucho más interés y lo recibió el 24 de enero. Amablemente le dijo que conocía bien Palestina y que debía ser de los judíos: "es sólo una cuestión de tiempo. Una vez que tengan medio millón de judíos..."; "pero no los dejan entrar" dijo Herzl; "tonterías -respondió el rey-todo se puede hacer con soborno". En cuanto a interceder ante el Sultán, le comunicó que lo consultaría. ${ }^{178}$ Sin embargo, de vuelta en Viena un telegrama le informaba que el gobierno italiano no podía hacer la petición al Sultán tal y como Herzl lo deseaba. ${ }^{179}$

Entre finales de 1903 y principios de 1904 Herzl lo intentó también con el gobierno de Viena sin mucho éxito. Finalmente consiguió una entrevista con el Secretario de asuntos exteriores en abril de 1904, quien estuvo de acuerdo con hacerle la petición al Sultán si los ingleses lo aceptaban. Es decir, no consiguió nada, ya que los ingleses no estaban dispuestos a hacerlo por temor de empujar todavía más al Sultán en los brazos del Kaiser.

176 Ibid., p. 403.

${ }^{177}$ Ibid., p. 421-2.

${ }^{178}$ Ibid., p. 425-7.

179 Ibid., p. 433. 


\section{Éxitos y fracasos de Herzl}

Herzl buscó desesperadamente un estado para su pueblo. Se inclinaba por Palestina por razones históricas y tácticas -Israel seguía estando en el inconsciente colectivo de millones de judíos- pero no descartó otras posibilidades. No le bastaban colonias aquí o allá -en Palestina o en Argentina. Entendía que esas soluciones no harían sino retrasar el antisemitismo: una vez que las colonias aumentaran, el odio al pueblo judío no tardaría en aparecer y las consecuencias podrían ser funestas. Por esa razón se lanzó a buscar apoyo en todas las direcciones que pudo hasta llegar al agotamiento. Sin tener dinero ni grandes apoyos tampoco cedió. Fue un maximalista político, lo que le llevó a enfrentarse a los grandes magnates judíos que le podían haber apoyado; aún así, sin el apoyo de éstos ni el de los grupos más organizados en ese momento - los Amantes de Sión- desarrolló una labor diplomática de altos vuelos, impensable antes de él. Se puede decir que a su muerte los resultados en ese terreno eran magros: muchas promesas pero nada en concreto. Quizá el error más grave de Herzl fue el de no entender la problemática del Imperio otomano, principal opositor a sus proyectos. Alemania primero e Inglaterra después, e incluso la antisemita Rusia podían haber obtenido beneficios del asentamiento de sus ciudadanos judíos en Palestina, sin embargo la total oposición de la Sublime Puerta cerró toda posibilidad. Sólo cuando ésta estaba a punto de caer -1917el gobierno de Su Majestad pudo ofrecer 'un hogar nacional' a los judíos de todo el mundo (Declaración Balfour).

El Imperio otomano sabía que con su veniat rompería el círculo vicioso: Alemania o Inglaterra apoyarían el movimiento de judíos hacia Palestina y, con la ayuda de los Estados, era altamente probable que las finanzas de los judíos acaudalados llegaran en unos momentos en donde el antisemitismo en el Este de Europa hacía estragos. Sin embargo, Herzl, según Oke, ${ }^{180}$ no fue consciente del enorme dilema que

${ }^{180}$ Kim Kemal Oke, "The Ottoman Empire, Zionism, and the Question of Palestine (1880-1908)," International Journal of Middle East Studies, 14, 3 (agosto, 1982), p. 330-1. 
enfrentaba la Sublime puerta. El Imperio estaba sufriendo el cáncer del separatismo en los Balcanes y en el este de la península de Anatolia el de los armenios, por lo que tenía miedo de alimentar otro movimiento nacionalista dentro de sus fronteras. A pesar de las buenas disposiciones de los sionistas, Constantinopla no se hacía ilusiones acerca del futuro del verdadero carácter de la emigración judía hacia Palestina. El embajador turco en Berlín describía su visión al Sultán: "No nos debemos hacer ilusiones acerca del sionismo. A pesar de que los conferenciantes en el Congreso [sionista] hablan de generalidades acerca del futuro del pueblo judío, los sionistas, en efecto, desean la formación de un gran Estado en Palestina, que se extenderá a los países limítrofes" ya que, según el embajador, como en Palestina no cabían los diez millones de judíos perseguidos a lo largo del mundo, acabarían extendiéndose. Cuando Herzl inició sus contactos con Chamberlain para situarse en el Sinaí, el Sultán debió pensar que el informe de su embajador era cierto.

Quizá sea cierto, tal como dice Oke, que Herzl no era consciente de esa situación, o quizá, sabiéndolo, pensó en jugarse el todo por el todo intentando preparar el camino para cuando cayera el Imperio otomano, lo cual era previsible que sucediera pronto como Herzl bien sabía.

Herzl murió sin ver hecho realidad sus sueños -situación con la que contaba ya desde que escribió El Estado judio- sin embargo fue él quien abrió las puertas de todas las cancillerías importantes a los sionistas. Sin su tenaz trabajo es difícil pensar que la declaración Balfour se hubiera dado pocos años después de su muerte y es muy probable que sin Herzl hoy día no estuviéramos hablando de un país llamado Israel.

Herzl no fue un gran intelectual del sionismo, o por lo menos no fue original en sus planteamientos, El Estado judio (1896) y Altneuland (1902) no tienen nada de novedad con respecto a otros sionistas o protosionistas como Pinsker o Hess. ${ }^{181}$ Sin embargo es considerado el

181 Avineri, op. cit., p. 105. 
padre del sionismo político. La razón es clara: fue quien convocó el Primer congreso sionista de la historia (Basilea, 1897) y el que fundó la Organización sionista mundial, pero sobre todo fue quien logró sacar el ideal sionista del estrecho círculo del pueblo judío para lanzarlo a la arena de la política mundial; ${ }^{182}$ es decir, supo manejar con especial destreza una de las armas más poderosas de la política del siglo XX: la opinión pública. $^{183}$

Como periodista de uno de los periódicos más influyentes en Austria y Alemania conocía el poder del papel impreso. Unos cuantos artículos podían encumbrar o humillar a un hombre o a un movimiento, pero sobre todo era consciente de que uno de los efectos más importantes de los periódicos era el de difundir una idea. Lo que podría tardar años en propagarse de boca en boca se producía en semanas, a veces días, si aparecía en el periódico adecuado en el momento adecuado. Así, hablando con un amigo quien le criticaba que su movimiento era sólo ruido le espetó: "El ruido lo es todo, le dije con enfado... Un ruido sostenido es en sí mismo un hecho notable. La historia mundial no es sino ruido: ...los hombres lo usan y todavía lo desprecian." "184 Quería que se hablara de él siguiendo el irónico adagio 'aunque se hable mal'; así a su amigo Güdemman, quien no se atrevía a hablar en la sinagoga del sionismo, le dijo también con enfado: "Por todo lo que me importa, habla en contra del sionismo, pero no te calles acerca de él. Puedes informar a la gente acerca de un asunto atacándolo toscamente o de otras formas. Ése es el arte de la oratoria". ${ }^{185}$ En los altos niveles también defendió esa forma de actuar. En una entrevista con Bülow -18 de septiembre de 1898-éste le preguntó por qué el Neue Freie Press -el periódico de Herzl- no había dicho nada acerca del Segundo congreso sionista y por qué el Frankfurter Zeitung lo había hecho de forma negativa. Herzl constestó que era debido a que los periódicos judíos liberales temían que se les acusara de poco patrio-

182 Ibid., p. 106.

${ }^{183}$ Ibid., p. 108.

${ }^{184}$ Lowenthal, ed., The Diaries of Theodor Herzl. p. 231.

${ }^{185}$ Ibid., ed. p. 201. 
tismo y continuó: "Es deplorable que nuestro movimiento sea conocido mediante caricaturas y chascarrillos, pero ...esto también fue al fin y al cabo un excelente medio para popularizar la idea." $" 186$

Herzl reconocía que fue en la cualidad de propagandista donde alcanzó su mayor éxito: ${ }^{187}$

A veces sucede que un hombre de valía tiene actividad en varios campos. Luego sucede que está seguro de ser reconocido únicamente en el campo que es periférico a su personalidad dominante.

Así, por ejemplo, me he convertido mundialmente famoso en una esfera en donde no he conseguido apenas nada desde el punto de vista intelectual... allí, en la cuestión judía, me he convertido en un renombrado propagandista.

Esas afirmaciones eran ciertas a medias; era cierto que no había conseguido nada tangible en su intensa labor diplomática, pero dejaba tras de sí la Organización sionista mundial y el Banco destinado a recaudar los fondos para la creación del Estado judío; es decir había hecho una labor política que superaba con creces la mediocridad. Pero sobre todo, y en eso sí llevaba razón, Herzl había dado a conocer al mundo el sionismo. Los que le siguieron ya tenían mucho terreno roturado. Ninguna cancillería importante en el mundo, tras la muerte de Herzl, desconocía lo que el sionismo quería. Es difícil pensar que hubiera sucedido lo mismo sin la labor hasta el agotamiento de un húngaro que siempre quiso ser germano y que acabó siendo sionista.

\section{Su muerte}

Poco después de volver de Italia se puso gravemente enfermo. A su amigo Hechler le dijo "diles que di mi sangre por mi pueblo". En su delirio compraba lotes de tierra en Palestina. El 3 de julio falleció a la edad de

186 Ibid., p. 238.

187 Ibid., p. 361. 
44 años. Herzl pidió que se le enterrara en Viena al lado de su padre hasta "que el pueblo judío me lleve a Palestina". Su atormentada odisea intelectual había llegado a su fin. El hombre que propuso el bautismo colectivo pasaba a la historia como el autor intelectual del Estado judío. El 16 de agosto de 1949 sus restos mortales volaban al estado de Israel y el 17 eran enterrados en lo que se llamó el Monte Herzl en Jerusalén. Herzl descansa guardado por el Estado por él soñado. Otros sueños del fundador del sionismo todavía están lejanos. 
La reproducción total o parcial de este artículo se podrá hacer si el ITAM otorga la autorización previamente por escrito. 